\title{
COMPARISON OF OUTCOMES BETWEEN EARLY AND DELAYED LAPAROSCOPIC CHOLECYSTECTOMY IN ACUTE CALCULOUS CHOLECYSTITIS
}

\author{
Muhammad Ismail, Nasir Mehmood Wattoo, Muhammad Qasim Butt, Fareeha Naz \\ Pak Emirates Military Hospital/National University of Medical Sciences (NUMS) Rawalpindi Pakistan, *Armed Forces Institute of Cardiology/National \\ University of Medical Sciences (NUMS) Rawalpindi Pakistan
}

\begin{abstract}
Objective: To compare early versus delayed laparoscopic cholecystectomy in acute calculous cholecystitis in terms of mean operative time, hospital stay, conversion rate to open surgery and post-operative complications.

Study Design: Quasi experimental study.

Place and Duration of Study: Army Liver Transplant Unit, Department of Surgery, Pak-Emirates Military Hospital Rawalpindi, from Jul to Dec 2018.

Methodology: A total of 170 patients (85 in each group) diagnosed as a case of acute calculous cholecystitis who met the sample selection criteria were included. Group A patients underwent early laparoscopic cholecystectomy within 72 hours of admission while group B patients underwent conservative management followed by delayed laparoscopic cholecystectomy after 6 weeks. All patients were followed for operative time, hospital stay, per-operative difficulties encountered and post-operative complications.

Results: Group A had a mean operation time of $43.9 \pm 11.1$ minutes, while group B had a mean operation time of $45.8 \pm$ 10.1 minutes $(p=0.83)$. The mean duration of hospitalization was $2.8 \pm 1.1$ days in group A and $5.3 \pm 0.8$ days in group B $(p<0.001)$. Complications were measured at a frequency of $14.1 \%$ in group A and $5.9 \%$ in group B $(p=0.07)$.

Conclusion: Early laparoscopic cholecystectomy is better than delayed laparoscopic cholecystectomy in acute calculous cholecystitis in terms of hospital stay and per-operative difficulties faced. The post-operative complications between the two groups are comparable.
\end{abstract}

Keywords: Acute calculous cholecystitis, Hospital stay, Laparoscopic cholecystectomy.

This is an Open Access article distributed under the terms of the Creative Commons Attribution License (https://creativecommons.org/licenses/by-nc/4.0/), which permits unrestricted use, distribution, and reproduction in any medium, provided the original work is properly cited.

\section{INTRODUCTION}

Cholelithiasis or gallstone disease constitutes a major public health problem that affects about $10-15 \%$ of the adult population of the world. The disease has a female preponderance ${ }^{1}$. The prevalence of cholelithiasis in Pakistan was found to be $10.2 \%^{2}$. Surgery is the mainstay of the treatment and since the middle of the $20^{\text {th }}$ century a number of surgical procedures and techniques have been introduced for performing cholecystectomy. The introduction of the laparoscopic cholecystectomy procedure in 1989 by Semm et al further increased the number of patients undergoing cholecystectomy ${ }^{3}$.

Cholecystectomy is one of the most commonly performed surgical procedure nowadays. Minimally invasive laparoscopic cholecystectomy has become the gold standard and a popular alternative to open cholecystectomy in benign gallbladder disease in modern surgical practice because of the advantages of early mobilization of the patient, decreased stay in hospital, rapid return to activity and better cosmesis ${ }^{3-5}$. For this reason it is also being performed as a daycare proce-

Correspondence: Dr Muhammad Ismail, Resident General Surgery, Pak Emirates Military Hospital, Rawalpindi Pakistan

Received: 25 Apr 2019; revised received: 19 Jun 2019; accepted: 25 Jun 2019 dure in some centers.

About $1-4 \%$ patients of cholelithiasis become symptomatic annually either due to development of acute cholecystitis or they present with biliary colic. Acute cholecystitis is one of the commonest indications for cholecystectomy ${ }^{6}$. The decision regarding the timing of surgery varies among surgeons. The proponents of early laparoscopic cholecystectomy report it to be a safe and feasible option in patients presenting with acute cholecystitis. The advantages reported being decreased hospital stay, decreased morbidity, a low conversion rate to open surgery and a low reoperation rate ${ }^{7,8}$.

The advocates of delayed laparoscopic chole-cystectomy have reported increased morbidity and complications with early laparoscopic cholecystectomy, when the two are compared. Delayed laparoscopic cholecystectomies have been shown to have a reduced risk of complication per-operatively as well postoperatively, with decreased rates of per-operative hemorrhage, decreased rates of bile duct injury, and a reduced risk of conversion to open cholecystectomy ${ }^{9}$. In fact, certain authorities still advocate that delayed laparoscopic cholecystectomy be employed in patients with moderate acute cholecystitis, the first-line treat- 
ment being anti-microbial therapy, with early laparoscopic surgery being reserved for patients with mild cholecystitis only ${ }^{10}$.

Both early and delayed laparoscopic cholecystectomies are performed in our population for patients presenting with acute calculous cholecystitis with the choice of optimal timing of surgery still a topic of great debate among surgeons. Therefore, we conducted this study with the objective of comparing early (within 72 hours) versus delayed (after 6 weeks) laparoscopic cholecystectomy in terms of operation time, hospital stay, peri-operative difficulties faced and post-operative complications. The findings of our study will help provide local evidence regarding optimal timing of laparoscopic cholecystectomy in acute calculous cholecystitis.

\section{METHODOLOGY}

A quasi experimental study was conducted from July to December 2018 in the Army Liver Transplant Unit, Department of Surgery, Pak-Emirates Military Hospital (PEMH), Rawalpindi on patients undergoing laparoscopic cholecystectomy, diagnosed as cases of acute calculous cholecystitis; who fulfilled the sample selection criteria, after approval from the ethics review committee of PEMH Rawalpindi. A written and informed consent (in a language understood by the patient) was signed by every patient included in the study. WHO sample size calculator was used to calculate the sample size taking confidence level $(1-\alpha)=95 \%$, Absolute precision required $(\mathrm{d})=0.07$, anticipated population proportion $1(\mathrm{p} 1)=1.3 \%{ }^{11}$ (conversion rate) and anticipated population proportion $2(\mathrm{p} 2)=10.7 \%{ }^{11}$. The sample size was calculated as $85+85=170$ patients. The sampling technique employed was consecutive nonprobability sampling.

The sample selection was done by employing the inclusion criteria constituting patients between the age of 20-70 years, having BMI between $20-35 \mathrm{~kg} / \mathrm{m}^{2}$, belonging to both genders and with ASA grades I-III. All patients included were diagnosed cases of acute calculous cholecystitis on ultrasonography of abdomen done by Armed Forces Institute of Radiology and Imaging. The exclusion criteria included patients with acute pancreatitis, obstructive jaundice, deranged liver function tests, diabetes mellitus, ischemic heart disease, ASA class IV \& V, renal failure and coagulopathies.

Patients were divided randomly by lottery method into two equal groups of 85 patients each. Patients in group A underwent early laparoscopic cholecys- tectomy for acute calculous cholecystitis within 72 hours of admission to the hospital while in group B patients were initially managed conservatively by intravenous antibiotics and were discharged from the hospital and then were recalled for laparoscopic cholecystectomy after 6 weeks.

Data were analyzed using SPSS-25. Mean and SD was calculated for quantitative variables like age, operation time and hospital stay. Qualitative variables like conversion rate to open surgery, surgical site infection, seroma and hematoma formation, bile leakage and bile duct injury were recorded in terms of frequency and percentages. Chi square test was applied to compare all qualitative and $\mathrm{t}$-test was used for quantitative variables. The $p$-value of $\leq 0.05$ was taken as statistically significant.

\section{RESULTS}

A total of 170 patients were enrolled and divided into two equal groups consisting of 85 patients each in this study. They comprised of 143 females (84.1\%) and 27 males $(15.1 \%)$. The mean age of patients was $45.6 \pm 10.1$ years (range $=23-67$ years). Mean age was $45.5 \pm 10.2$ years (range $=23-63$ years) for patients in the early laparoscopic surgery group (group A) and $45.8 \pm$ 10.1 years (range=26-67 years) for patients in the delayed laparoscopic surgery group (group B). The BMI of all enrolled patients was found to be $28.8 \pm 3.3 \mathrm{~kg} / \mathrm{m}^{2}$ (range $=23.1-35.3 \mathrm{~kg} / \mathrm{m}^{2}$ ). Mean BMI for patients in group A was $29.2 \pm 3.2 \mathrm{~kg} / \mathrm{m}^{2}\left(\right.$ range $\left.=23.3-35.3 \mathrm{~kg} / \mathrm{m}^{2}\right)$ and $28.4 \pm 3.3 \mathrm{~kg} / \mathrm{m}^{2}$ (range $\left.=23.1-35 \mathrm{~kg} / \mathrm{m}^{2}\right)$ for patients in group B. The frequency of patients according to ASA scale were $37(43.5 \%), 40(47.1 \%)$ and $8(9.4 \%)$ for ASA I, II \& III respectively in group A, and 28 (32.9\%), $53(62.4 \%)$ and $4(4.7 \%)$ in group B respectively, which was statistically insignificant $(p=0.11)$ (fig-1).

The total mean operation time for both groups was $42.4 \pm 11.1$ minutes (range=25-85 minutes). In group $\mathrm{A}$, the mean operation time was $43.9 \pm 11.1 \mathrm{~min}$ utes (range $=25-79$ minutes) while in group $B$, the mean operation time was $40.9 \pm 11.1$ minutes (range $=26-85$ minutes). The operative time between the two groups was statistically insignificant $(p=0.34)$ (table).

The total mean hospitalization time for both groups was $4 \pm 1.6$ days (range $=1.1-8.1$ days). In group A, the mean hospitalization time was $2.8 \pm 1.1$ days (range $=1.1-7.3$ days) while in group $B$, the mean hospitalization time was $5.3 \pm 0.8$ days (range $=2.5-8.1$ days). The hospitalization time between the 2 groups was statistically significant $(p<0.001)$ (table). 
Both groups of patients were observed for complications which included rate of conversion to open surgery, surgical site infections, formation of seroma / hematoma, biliary leakage and bile duct injury. Total rate of conversion to open cholecystectomy was $4.7 \%$ (8 out of 170 cases) with $5.8 \%$ (total 5 patients out of 85 ) in group A and 3.5.

Table: Demograhic detail of included participant.

\begin{tabular}{l|c|c|c}
\hline & $\begin{array}{c}\text { Group A } \\
(\mathbf{n = 8 5})\end{array}$ & $\begin{array}{c}\text { Group B } \\
(\mathbf{n = 8 5})\end{array}$ & $\begin{array}{c}p \text { - } \\
\text { value }\end{array}$ \\
\hline Gender (M:F) & $\begin{array}{c}13(15.3 \%): 72 \\
(84.7 \%)\end{array}$ & $\begin{array}{c}14(16.5 \%): 71 \\
(83.5 \%)\end{array}$ & 0.83 \\
\hline Age (Years) & $45.5 \pm 10.2$ & $45.5 \pm 10.1$ & 0.66 \\
\hline BMI (kg/m $)$ & $29.2 \pm 3.2$ & $28.4 \pm 3.3$ & 0.43 \\
\hline $\begin{array}{l}\text { Operation } \\
\text { Time (Minutes) }\end{array}$ & $43.9 \pm 11.1$ & $40.9 \pm 11.1$ & 0.34 \\
\hline $\begin{array}{l}\text { Hospitalization } \\
\text { Time (days) }\end{array}$ & $2.8 \pm 1.1$ & $5.3 \pm 0.8$ & $<0.00$ \\
\hline Complications & $12(14.1 \%)$ & $5(5.9 \%)$ & 0.07 \\
\hline Conversion & $5(5.8 \%)$ & $3(3.5 \%)$ & 0.47 \\
\hline Site Infection & $1(1.2 \%)$ & $2(2.4 \%)$ & 0.56 \\
\hline $\begin{array}{l}\text { Seroma } \\
\text { /Hematoma }\end{array}$ & $2(2.4 \%)$ & - & 0.15 \\
\hline Biliary Leakage & $1(1.2 \%)$ & - & 0.32 \\
\hline $\begin{array}{l}\text { Bile Duct } \\
\text { Injury }\end{array}$ & $3(3.5 \%)$ & - & 0.08 \\
\hline
\end{tabular}

In group B (total 3 out of 85), with a $p=0.47$, which was statistically insignificant. Incidence of surgical site infections was 3 out of 170 cases $(1.7 \%)$ with 1 case in group A $(1.2 \%)$ and 2 cases in group B $(2.4 \%)$, with $p=0.56$, which was statistically insignificant. Sero$\mathrm{ma} /$ hematoma formation was documented in 2 patients $(1.2 \%)$ out of 170 . Both cases occurred in group A $(2.4 \%)$, while group B had no cases $(0 \%), p$-value $=0.15$, which was also statistically insignificant. Biliary leakage was noted in only $1(0.6 \%)$ case, and it occurred in group A with a total incidence of $1.2 \%$, while no cases were reported in group B $(p=0.316$, statistically not significant). Lastly, 3 (1.8\%) cases were documented to have bile duct injury, all of which occurred in group A $(3.5 \%)$, with the rate in group B at $0 \%$, the calculated $p$ value was 0.08 , which was statistically insignificant. A total number of $17(10 \%)$ cases developed complications, of which 12 occurred in group A (14.1\%), and 5 occurred in group B (5.9\%), with a $p=0.07$, which was not significant statistically (fig-1 \& 2).

\section{DISCUSSION}

This study showed a preponderance of female patients with female patients making $84.1 \%$ of all patients. The reason for this was that families of military personnel of Pakistan Armed Forces are entitled in Pak Emirates Military Hospital, Rawalpindi. Conversely, a research protocol conducted by Kohga et al studied reported a male preponderance with the study comprising of $63.2 \%$ male patients, while Gutt et al reported a more balanced gender distribution with $58.7 \%$ females and $41.3 \%$ males ${ }^{11,12}$.

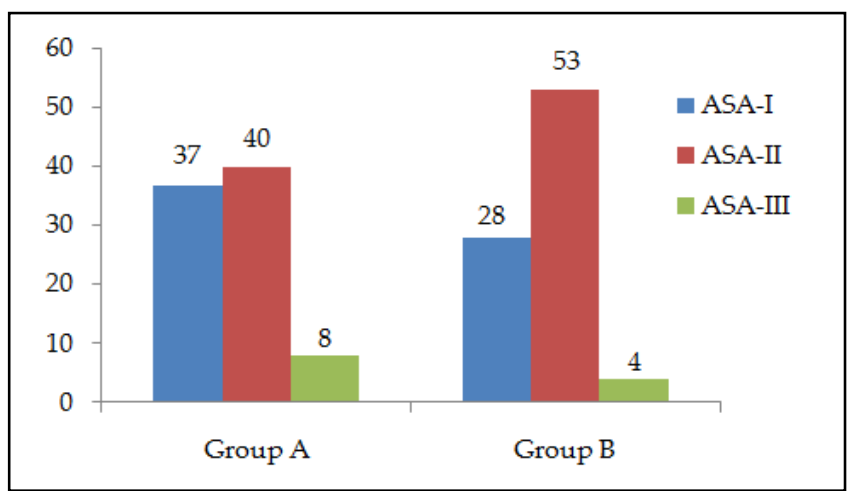

Figure-1: ASA classes.

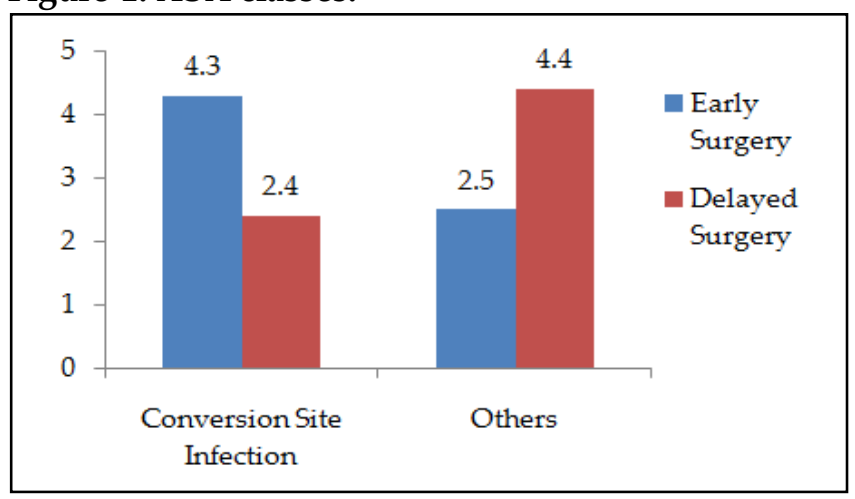

Figure-2: Complications in early and delayed surgery.

Total mean age of patients was $45.6 \pm 10.1$ years in our study. Sheikh et al conducted a similar study from Jamshoro in 2017 and reported a population with a much younger total mean age of $35.2 \pm 4.9$ years $^{13}$. Another study conducted by Kolla et al in 2004 in New Delhi found a mean age which was closer to our result: $41.5 \pm 11.4$ years in the early surgery group and $38.6 \pm 11.4$ years in the delayed group with a $p$-value of $0.44^{14}$. The values were in stark contrast to Ozkardes et al and Gutt et al who reported a much older mean age of $58.0 \pm 10.4$ years and $55.6 \pm 16.3$ years in the early surgery group and $59.4 \pm 16.6$ years and 56.8 \pm 17.1 years in the delayed group, respectively ${ }^{9,12}$.

In our study, the mean BMI was $29.2 \pm 3.2 \mathrm{~kg} / \mathrm{m}^{2}$ in the early procedure group and $28.4 \pm 3.3 \mathrm{~kg} / \mathrm{m}^{2}$ in the delayed group, with a $p$-value of 0.43 . Gutt et al reported a similar BMI in their study with figures of $28.9 \pm 5.8 \mathrm{~kg} / \mathrm{m}^{2}$ in the early group and $29.5 \pm 6.6$ $\mathrm{kg} / \mathrm{m}^{2}$ in the delayed group ${ }^{12}$. Roulin et al reported a 
similar BMI $28.2 \pm 5.5 \mathrm{~kg} / \mathrm{m}^{2}$ in the early procedure group but a slightly lower number i.e. $27.6 \pm 4.3 \mathrm{~kg} / \mathrm{m}^{2}$ in the delayed group, with a $p$-value of 0.4915 .

The mean operation time in the early group in our study was $43.9 \pm 11.1$ minutes while it was $40.9 \pm$ 11.1 in the delayed group, with a $p$-value of 0.34 which was not significant. Agarwal et al reported a higher mean operation time of $69.4 \pm 29.6$ minutes in the early group, and $66.4 \pm 15.9$ minutes in the delayed group, with a $p$-value of 0.8 which was not significant as in our study ${ }^{16}$. Lai et al reported a greatly increased mean operation time of $122.8 \pm 36.0$ minutes in the early group, and $106.6 \pm 37.3$ minutes in the delayed group, with a statistically significant $p$-value of 0.04 , in contrast to our result.

Mean hospitalization time was $2.8 \pm 1.1$ days and $5.3 \pm 0.8$ days and a statistically significant $p$-value of $<0.0001$, in our study. Kolla et al reported a total mean hospitalization time of $4.1 \pm 8.6$ days in the early group and $10.1 \pm 6.1$ days in the delayed group, with a $p$ value of 0.023 . Lai et al reported a markedly high total hospital stay in the early group at $7.6 \pm 3.6$ days in comparison to $11.6 \pm 3.4$ days in the delayed group, with a $p$-value $<0.001$. All studies reported a statistically significant reduction in hospital stay in early surgeries when compared to delayed ones.

Conversion rate to open cholecystectomy for both groups in our study was $5.8 \%$ and $3.5 \%$ for early and delayed procedures respectively, the difference between the groups being statistically insignificant $(p=$ 0.47). Agarwal et al reported a similarly insignificant $p$-value of 0.67 , albeit at higher rates: $16 \%$ and $8 \%$ in early and delayed groups respectively. However, with Kohga et al reported a conversion rate of $1.3 \%$ in early group and $10.7 \%$ in delayed group with a statistically significant $p$-value of $<0.001$.

Peng et al ${ }^{18}$ reported a conversion rate in $19 \%$ of patients in the early group, and $4 \%$ in the delayed group with a significant $p$-value of 0.002 . Saber et al ${ }^{19}$ reported a conversion rate in $5 \%$ of patients in early group, and 1.7 percent in delayed.

Complications (including surgical site infection, biliary leakage and bile duct injury) were reported in 12 patients $(14.1 \%)$ in the early laparoscopic cholecystectomy group and 5 patients $(5.9 \%)$ in the delayed laparoscopic cholecystectomy group which was statistically insignificant $(p=0.07)$. Agarwal et al reported a total complication rate of $24 \%$ in the early group and $8 \%$ in the delayed group, with a $p$-value of 0.08 , which was also statistically insignificant. In contrast, Ozkar- des et al reported a total complication rate of $26.7 \%$ in the early group and $0 \%$ in the delayed group, with a $p$-value of 0.002 , which was statistically significant. Of significance, surgical site infection was recorded at $1.2 \%$ and $2.4 \%$ in early and delayed procedures respectively, with a statistically insignificant $p$-value of 0.56 in our study which was similar to Saber et al who reported an infection rate of $5 \%$ in the early group, and $3.4 \%$ in the delayed group. Kolla et al showed disparate results, reporting an infection rate of $10 \%$ in the early group, and $20 \%$ in the delayed group.

Early laparoscopic surgery provides a safe, efficacious and cost-effective therapeutic option in the treatment of acute calculous cholecystitis. Evidence is strong that complications associated with early surgery are comparable to those in delayed procedures and should not be a reason to delay surgery. A significant reduction in hospital stay results in a favorable cost-benefit ratio, which in itself is a compelling reason to opt for an early procedure. Emphasis on reduction in complications, with adequate training in laparoscopic techniques, thorough intra-abdominal irrigation and adequate drainage tube placement can go a long way in reducing the already statistically insignificant complication rates. With comparable mean procedure times, early laparoscopic cholecystectomy appears to be an overall better therapeutic option when compared to delayed laparoscopic cholecystectomies, with conversion to open cholecystectomies occurring at similar frequencies. With the advent of robotic assisted laparoscopic cholecystectomy, albeit at an early stage, complication rates of early laparoscopic surgery can be expected to drop in the near future ${ }^{20}$. Limitations of our study, that are pertinent to mention, include our mainly female population, short duration of study, variable time between onset of symptoms and reporting to hospital and small sample size. Further research is required on the topic with a larger sample, and to determine long term morbidity and patient satisfaction rates.

\section{CONCLUSION}

In summary, early laparoscopic cholecystectomy appears to be a safe and reliable therapeutic option for managing patients presenting with acute cholecystitis, which has a safety profile, duration of surgery, conversion and complications rate that are comparable to delayed laparoscopic cholecystectomy, with the added benefit of shorter hospital stay and decreased costs, which is of paramount importance in a developing country like Pakistan. 


\section{CONFLICT OF INTEREST}

This study has no conflict of interest to be declared by any author.

\section{REFERENCES}

1. Stinton LM, Shaffer EA. Epidemiology of gallbladder disease: Cholelithiasis and Cancer. Gut Liver 2012; 6(2): 172-87.

2. Bilal M, Haseeb A, Saad M, Ahsan M, Raza M, Ahmed A, et al. The prevalence and risk factors of gall stone among adults in Karachi, South Pakistan: A Population-Based study. Glob J Health Sci 2016; 9(4): 106-14.

3. Coccolini F, Catena F, Pisano M, Gheza F, Fagiuoli S, Di-Saverio $\mathrm{S}$, et al. Open versus laparoscopic cholecystectomy in acute cholecystitis. Systematic review and meta-analysis. Int J Surg 2015; 18: 196-204.

4. Haribhakti SP, Mistry JH. Techniques of laparoscopic cholecystectomy: Nomenclature and selection. J Minim Access Surg. 2015; 11(2): 113-18.

5. Al-Mulhim AA. Current trends in laparoscopic cholecystectomy. J Family Community Med 1997; 4(2): 33-40.

6. Gurusamy KS, Davidson C, Gluud C, Davidson BR. Early versus delayed laparoscopic cholecystectomy for people with acute cholecystitis. Cochrane Database Syst Rev 2013; (6): CD005440.

7. Blohm M, Österberg J, Sandblom G, Lundell L, Hedberg M, Enochsson L. The sooner, the better? the importance of optimal timing of cholecystectomy in acute cholecystitis: data from the national swedish registry for gallstone surgery, Gall Riks. J Gastrointest Surg 2016; 21(1): 33-40.

8. Banz V, Gsponer T, Candinas D, Güller U. Population-based analysis of 4113 patients with acute cholecystitis: defining the optimal time-point for laparoscopic cholecystectomy. Ann Surg 2011; 254(6): 964-70.

9. Ozkardes AB, Tokac M, Dumlu EG, Bozkurt B, Ciftci AB, Yetisir F, et al. Early versus delayed laparoscopic cholecystectomy for acute cholecystitis: A prospective, randomized study. Int Surg 2014; 99(1): 56-61.

10. Miura F, Takada T, Strasberg SM, Solomkin JS, Pitt HA, Gouma
DJ, et al. TG13 flowchart for the management of acute cholangitis and cholecystitis 2013; 20(1): 47-54.

11. Kohga A, Suzuki K, Okumura T, Yamashita K, Isogaki J, Kawabe A, et al. Outcomes of early versus delayed laparoscopic cholecystectomy for acute cholecystitis performed at a single institution. Asian J Endosc Surg 2019; 12(1): 74-80.

12. Gutt CN, Encke J, Köninger J, Harnoss JC, Weigand K, Kipfmüller K, et al. Acute cholecystitis: early versus delayed cholecystectomy, a multicenter randomized trial (ACDC study, NCT 00447304). Ann Surg 2013; 258(3): 385-93.

13. Shaikh AR, Ali SA, Munir A, Shaikh AA. Single incision laparoscopic cholecystectomy with conventional instruments and ports: Initial experience at tertiary care public sector hospital. Pak J Med Sci 2017; 33(3) :654-58.

14. Kolla SB, Aggarwal S, Kumar A, Kumar R, Chumber S, Parshad $\mathrm{R}$, et al. Early vs delayed laparoscopic cholecystectomy for acute cholecystitis: A prospective randomized trial. Surg Endosc 2004; 18(9): 1323-27.

15. Roulin D, Saadi A, Di Mare L, Demartines N, Halkic N. Early versus delayed cholecystectomy for acute cholecystitis, are the 72 hours still the rule?: A randomized trial. Ann Surg 2016; 264(5): 717-22.

16. Agarwal R, Sood KC, Agarwal B. Evaluation of early versus delayed laparoscopic cholecystectomy in acute cholecystitis. Surg Res Pract 2015; 2015: 349801.

17. Lai PBS, Kwong KH, Leung KL, Kwok SPY, Chan ACW, Chung SCS. Randomized trial of early versus delayed laparoscopic cholecystectomy for acute cholecystitis. Br J Surg 2003; 85(6): 764-67.

18. Peng WK, Sheikh Z, Nixon SJ, Paterson-Brown S. Role of laparoscopic cholecystectomy in the early management of acute gallbladder. Br J Surg 2005; 92(5): 586-91.

19. Saber A, Hokkam EN. Operative outcome and patient satisfaction in early and delayed laparoscopic cholecystectomy for acute cholecystitis 2014; 2014: 162643.

20. Roh HF, Nam SH, Kim JM. Robot-assisted laparoscopic surgery versus conventional laparoscopic surgery in randomized controlled trials: A systematic review and meta-analysis. PLoS One 2018; 13(1): e0191628. 